\title{
Música y drogodependencias: análisis de algunos tópicos sobre drogas encontrados en la música
}

\author{
José Guillermo Fouce Fernández \\ Coordinador CAID Torrejón de Ardoz (Madrid) \\ Enviar correspondencia a:
}

José Guillermo Fouce. C/ Martín de Vargas, n 15, 2 B, 28005 Madrid, España. Guiller@correo.cop.es

\section{RESUMEN}

La música es un elemento clave en la cultura juvenil. Se analiza la presencia de una serie de tópicos-clasificados en 10 temáticas- relacionados con las drogodependencias que encontramos en las letras de canciones de cuatro estilos musicales: pop, rock, punk y cantautor en un total de 323 composiciones, analizando un total de 489 referencias que se hacen a la droga. Los 10 temas analizados son: proceso de drogadicción, su legalización y la relación de las drogas con "vivir al día," la música, con evadirse, las drogas en el ocio, la diversión y el tiempo libre, las relaciones sociales y sexuales, sus consecuencias y con diversos estilos de vida, así como su uso como metáforas y comparaciones. Encontramos una alta presencia de estos tópicos en las letras analizadas y una amplia diferenciación en el trato que a las drogodependencias dan los diferentes estilos musicales analizados todo lo cual refuerza una la hipótesis de partida: la presencia acrítica y cultural del consumo de drogas entre los jóvenes lo que puede influir en una baja percepción de riesgos.

Palabras clave: música, drogodependencias, juventud, adolescencia.

\section{ABSTRACT}

Music is a key element in juvenile culture. We look at the presence of a number of topics -classified in 10 groups- related to drug dependency that we found in the lyrics of songs in four musical styles: pop, rock, punk and performers singing their own songs in a total of 323 compositions, and analysed a total of 489 references to drugs. The 10 analyzed topics are: drug addiction process, their legalisation and their relationship with "living from one day to the next", music, with escape, drugs and leisure, amusement and free time, social and sexual relationships, their consequences and with diverse styles of life, as well as their use as metaphors and comparisons. We found a high presence of these topics in these lyrics and a wide differentiation in the treatment given to drug dependencies by the different musical styles analysed, all of which reinforces the basic hypothesis of the uncritical and cultural presence of drug use among the young, which could lead to a low risk perception.

Key words: music, adolescence, youth, drugs.

\section{INTRODUCCIÓNY FUNDAMENTACIÓN}

$\mathbf{E}$ I elevado consumo de drogas por jóvenes y ado- lescentes en la sociedad occidental, el inicio en este consumo progresivamente más temprano y las pautas de uso de estas sustancias asociadas al ocio de fin de semana, llevan a que surja una gran preocupación social por este fenómeno.

Por ese motivo, hemos considerado de gran importancia, analizar alguno de los factores que pueden estar influyendo en el consumo juvenil de las drogas. En esta dirección, puede afirmarse hoy, que el consumo de drogas no depende de un solo factor, sino de la suma de varios factores: la persona (personalidad, estado de ánimo, etc.), la sustancia (efectos físicos etc.) y la situación o contexto en que se consume. Dado que el mayor consumo de sustancias en la adolescencia se produce asociado a una situación de ocio y diversión (los fines de semana, en discotecas y pubs) donde la música está presente, y dado que la música es uno de los factores más importantes de la cultura juvenil hemos considerado importante analizar las letras musicales y los mensajes relacionados con las drogas para observar en qué medida se encuentra la droga en la música y qué mensajes se lanzan en los textos musicales. Como elemento importante de la cultura juvenil, y teniendo en cuenta la importancia de la cultura como factor influyente en las actitudes, creencias y comportamientos, sería lógico pensar que la 
música podría estar influyendo en el consumo de drogas de los adolescentes.

El presente trabajo surge del estudio anterior ("Drogas y menores") que se presentó en el V Encuentro de Psicología y drogodependencias del Colegio Oficial de Psicólogos de Madrid. Para analizar las temáticas se partirá del análisis previo desarrollado en dicho estudio, que analizaba descriptivamente la asociación entre drogas-jóvenes-música. En el actual, hemos ampliado la muestra de canciones y hemos analizado también el tipo de drogas mencionadas.

\section{MODELOTEÓRICO}

Partimos de plantearnos que la comprensión del complejo mundo de las drogodependencias y sus motivaciones debe girar en torno a un triángulo básico identificador de las variables a analizar:

- El sujeto (motivaciones individuales, valores, variables de personalidad...)

- La sustancia (efectos bioquímicos, consecuencias en la salud)

- La sociedad (representaciones o imágenes sociales, contextos y pautas de consumo, modelos sociales, cultura, normas sociales y grupos de pertenencia).

Conceptualizar así el complejo y extenso fenómeno de las drogodependencias nos lleva a complicar los análisis, situándonos en la necesidad de analizar los tres conjuntos de variables mencionados, que además están en constante interacción; no serviría, salvo como efecto deformador, tratar de simplificar la realidad si está no es simple.

Lo mismo acontecería si tratásemos de desarrollar acercamientos demasiado cerrados o científicamente "duros" de causa-efecto, la drogodependencia es un fenómeno multicausal y en constante evolución.

El modelo bio-psico-social tratará de integrar las dimensiones, factores y variables psicológicas, sociales y biológicas o, si lo preferimos: droga, persona y ambiente. La drogodependencia es un proceso (tanto en lo que respecta a la adquisición, como al mantenimiento y la extinción) complejo en el que la interacción entre múltiples factores es lo fundamental.

Tomando como guía sintética y ejemplo de este modelo bio-pisco-social, el modelo desarrollado por Mayor (1996:1-12) podemos identificar los siguientes elementos:

- DROGA: componente básico, ya que sin ella no hay drogodependencia, aunque depender de una droga sea una conducta.
- SUJETO: expectativas, elaboración cognitiva de valores y contexto, conciencia, autocontrol y autoestima, toma de decisiones...

- CONTEXTO: "propiedad tan propia del hombre que podríamos denominar a éste como "animal contextualizador" ya que es capaz de tomar en cuenta todas las posibilidades contextuales, pero selecciona la que resulta efectiva, trabaja sobre una realidad, pero la transforma y recrea e interactúa con el entorno de forma abierta e inagotable pero, a la vez, construyes un nicho ecológico en cuanto que es relevante para él" (p.7). Tiene un peso tan importante como el sujeto o la droga y puede funcionar como factor predisponente y/o precipitante, formando parte de la propia actividad (ej. modalidad de administración) y siendo afectado por ella.

Funes (1996), a partir de planteamientos similares, aplicados a jóvenes, adolescentes y menores, señalando las siguientes variables como las más relevantes:

a) Las expectativas, lo que se espera obtener al consumir y que vendrá influido por la moda, la televisión, la publicidad, las relaciones interpersonales, etc.

b) La Institucionalización: el cómo se usa la droga, su ritualización, su ambiente institucionalizado, los valores asociados.

c) La relación social: desde el planteamiento de que usar una droga es siempre un posicionamiento con respecto a los demás, y por tanto, debemos analizar el contexto grupal, las relaciones.

d) La búsqueda de identidad: presentaciones, imágenes y disfraces, gestos y lenguajes; "las drogas ayudan a ser" (p.10). En el contexto de los adolescentes cobra una especial relevancia la pregunta (vivencia) de quién soy y quién seré y ciertos consumos pueden contribuir a encontrar alguna respuesta aunque esta se presente como inadecuada.

e) El contexto vital en que se usan.

f) Las drogas y sus efectos.

g) Los ejes en torno a los que gira su vida diaria, la persona es función de lo que hace.

h) Las culturas de referencia: el sentido de las drogas en sus vidas.

El mismo autor señalará como "las apariencias engañan: a veces no deben ser las drogas el objeto de intervención" (p.6) sino más bien el contexto, en todos sus sentidos, que las hace funcionales y adaptativas, o el sujeto, es decir, las variables, necesidades o factores a los que puede estar respondiendo y, al tiempo ocultando el consumo de drogas. Además, plantea dos ideas claves: "nunca podemos decir que 
las conductas de los adolescentes carecen de sentido... la explicación de sus usos suele estar a menudo fuera de las drogas" (p.9), es decir, que las drogas y su uso tienen una funcionabilidad clara y por ello se consumen y debemos tratar de buscar esa funcionabilidad desde la lógica de los consumidores y no desde la nuestra si no queremos cometer sesgos que nos hagan perder el verdadero sentido de los consumos, "la atención a los adolescentes con usos problemáticos de drogas comienza por descubrir para qué le sirven esos usos en su vida" (p.12).

\section{CULTURA JUVENIL}

La cultura juvenil o mejor las culturas juveniles (por la alta heterogeneidad de los jóvenes como colectivo) pueden definirse (siguiendo a Feixa 1998) en sentido amplio, como las experiencias sociales de los jóvenes expresadas colectivamente mediante la construcción de estilos de vida distintivos, localizados fundamentalmente en el tiempo libre o en espacios intersticiales de la vida institucional.

En sentido más restringido pueden definirse estas culturas como la aparición de "micro sociedades juveniles" con altos grados de autonomía con respecto a las instituciones adultas, dotándose de espacios y tiempos específicos, que se configuran históricamente en los países occidentales tras la segunda guerra mundial coincidiendo con grandes procesos de cambio social en el terreno económico, educativo, laboral e ideológico. Estas micro sociedades han venido denominándose sub culturas, aunque sería mejor utilizar el término cultura para evitar estereotipos o etiquetas cargadas de valor desviacionista o minusvalorador (como ocurre con el prefijo sub: por debajo).

Las culturas juveniles se refieren pues, a culturas subalternas, así Gramsky (en Feixa, 1998) las identifico con las culturas de los sectores dominados, caracterizadas por una precaria integración en la cultura hegemónica.

Las culturas juveniles no son homogéneas ni estáticas, tienen fronteras laxas, intercambios de estilo numerosos, los jóvenes reciben influencias de varios estilos y culturas y, a menudo, construyen su propio estilo.

\section{MÚSICA}

La música, por su parte, es una de las manifestaciones culturales más potentes, repetida y atendida por los jóvenes. Por lo que estudiar la música puede ayudarnos a desvelar las manifestaciones y contenidos de las culturas juveniles.

La música es un elemento clave de la cultura juvenil, así con respecto a las actividades que los jóvenes desarrollan en su tiempo libre, encontramos que la gran mayoría (77.9\%) lo ocupa estando con los amigos, asistiendo a espectáculos (40.4\%), escuchando música en casa $(37 \%)$ y oyendo la radio $(16.1 \%)$ (Agencia Antidroga, 1998).

Otros estudios (Elzo, Orizo y otros, 1999) señalan también esta relevancia de la música: un 59,9\% de los jóvenes manifiestan haber asistido a algún espectáculo de música moderna (rock, pop...) al aire libre o en grandes espacios en los últimos 12 meses y sólo un $13 \%$ no lo ha hecho nunca; con respecto a lo que atrae de este tipo de espectáculos un 60,8\% de los jóvenes manifiestan que les atrae la música en sí, la música en directo, un 45, 5\% el ambiente que se forma en los conciertos; con respecto a las actividades, un 95,4\% manifiesta escuchar cintas o C.D. como una actividad tradicional en la que ocupar su tiempo libre; por último, preguntados los jóvenes sobre sus preferencias musicales, el mencionado estudio señala que un $11,7 \%$ de los jóvenes eligen el punk como su estilo favorito (un $60 \%$ elegirían el pop y los cantautores; un 30,5\% el bakalao; un 23,4\% el rock; un $19,1 \%$ el rock alternativo, un $16 \%$ el ska o reagee, un $11,7 \%$ el heavy, un $10,4 \%$ el soul y un $9,6 \%$ el rap o hip hop). Con estos datos se puede observar la gran importancia que la música tiene dentro de la juventud.

Estos datos pueden además reforzarse, desde una perspectiva europea si atendemos, por ejemplo, a lo señalado en varios estudios europeos realizados por Irefrea (Calafat et al, 1999, 2001). En estos trabajos se señala y analiza pormenorizadamente desde una perspectiva comparada la importancia de la noche, la fiesta y la música en la configuración de las culturas y subculturas juveniles estableciendo relaciones entre estilos musicales y pautas de consumo de drogas (alcohol, cannabis y éxtasis): "una de las áreas donde los jóvenes expresan su singularidad es en la esfera recreacional, el lugar en el que los jóvenes se muestran a sí mismos como realmente son... creando códigos de identificación como generación y como grupo" (Calafat et al, 2001:113)..

Así, se establece "una relación directa entre el estilo musical preferido y el uso de ciertas drogas, y que esta interrelación es otra de las características fundamentales de las subculturas juveniles" (Calafat et al, 1999:163); "en conclusión se puede establecer una clara relación entre la cultura recreativa y el uso de drogas... aparece tan hay una cierta relación entre el estilo musical preferido y el estilo de relación con la droga" (Calafat et al, 1999: 165) 
Otra apreciación clásica es señalar que los jóvenes se encuentran inmersos en una relación cultural con la droga. Así por ejemplo, salir los fines de semana por locales donde se pone música y se baila va muy asociado por ejemplo con el consumo de alcohol, es algo natural estar con los amigos sosteniendo una copa, es la imagen típica de la noche, es ahora cuando además, los fumadores ocasionales fuman y los bebedores ocasionales beben.

Pero resultaría demasiado extenso y pretencioso por nuestra parte tratar de analizar la música que escuchan los jóvenes en su globalidad, nos encontraríamos con un campo extensísimo y ampliamente diverso e inabarcable, con pocas cosas en común, a menos que lo seccionemos reduciéndolo en partes; queremos pues analizar una de esas posibles partes (la música rock, pop, de cantautor y punk en concreto) a desarrollar como inicio de una línea de investigación y conocimiento a desarrollar posteriormente.

\section{METOdOLOGÍA}

Nuestro objetivo al realizar esta investigación es describir qué tipo de mensajes relacionados con la droga están llegando a la juventud española en los últimos 15 años, a través de la música en este mismo idioma (una parte de la música, no toda). Con ello, podremos hacernos una idea de que clase de información llega a la juventud a través de este medio.

Lo primero que hemos hecho, por lo tanto, ha sido seleccionar unas canciones determinadas, ya que la tarea de analizar todos los temas existentes es inabarcable. A la hora de decidir que temas elegir y que temas no elegir, hemos optado por seleccionar aquellos grupos más conocidos según el estilo musical concreto a analizar.

¿Cómo saber cuáles son estos grupos? Hemos considerado que son aquellos que más se venden, que más se ponen en las emisoras de radio, en los pubs o en las discotecas y que más son referidos por los propios jóvenes. Así pues, hemos consultado las listas de éxitos de diversos medios, las listas de ventas, y la prensa especializada en música, que ofrece una visión de cuáles son los intérpretes de mayor éxito en los últimos años según los diferentes estilos musicales considerados. Cabe señalar que en el caso de la música punk, estos criterios no sirven, ya que se trata de un estilo mucho menos comercial, escuchado en ámbitos diferentes. En este estilo, hemos seleccionado a los intérpretes que las personas seguidoras de este tipo de música señalan como los más oídos.

Una vez seleccionados los intérpretes (67), hemos realizado una revisión por su discografía, descartando todas aquellas canciones que no traten el tema de la droga (ya que nuestra intención no es conocer en que proporción se habla o no de droga en las canciones de estos autores, sino analizar los casos en que se hable de ella).

El resultado final (nuestra muestra, por tanto) son 323 canciones de estos intérpretes, en los que explícitamente se menciona en 489 ocasiones algo relacionado con las drogas.

En cuanto a los estilos musicales, consideramos cuatro: pop, rock, punk y cantautor. Estos estilos están representados con diferente número de temas, ya que en la vida real la proporción de los temas que se escuchan de un estilo u otro también es desigual. Así, hemos seleccionado las siguientes referencias por estilo:

- Pop (99 temas: $30.65 \%$ del total): incluyendo poplatino (10 temas) y pop-flamenco (5 temas).

- Rock (72 temas: $22.29 \%$ del total)

- Punk (84 temas: $26.00 \%$ del total)

- Cantautores (68 temas: $21.05 \%$ del total)

Evidentemente, hay otros estilos musicales presentes en la cultura juvenil (hip- hop. House, techno...) pero elegimos estos por que nos resultaba excesivamente complejo tratar de abarcar todo el amplísimo espectro musical.

Tras realizar una primera observación de los temas seleccionados, decidimos concentrar la información que de ellos surgía en diez mensajes. Teniendo en cuenta, que en una misma canción puede darse más de un mensaje, la muestra final de mensajes fue de 489 (en los cuatro estilos). Los mensajes serían los siguientes:

1. Proceso de drogadicción: letras que recojan todas o algunas de las fases propias de una drogadicción, el comienzo, la dependencia, y el desenlace, ya sea este el abandono de la droga o la muerte.

2. Droga para olvidar, superar dificultades o evadirse: son los temas que contengan en sus letras a las drogas como un medio de evadirse de la realidad, superar penas, problemas, dificultades, desamores o directamente para intentar olvidarlas.

3. Droga en el ocio, la diversión y el tiempo libre: aquellas canciones donde se mencionan las drogas como fuente de diversión, ocio y modo mejor de pasar los ratos libres que uno tiene.

4. Droga en las relaciones sociales y sexuales: temas que muestren que la droga sirve para facilitar o entorpecer las relaciones sociales (principalmente las relaciones con los amigos) y las relaciones sexuales.

5. Consecuencias de las drogas: letras en las que se mencionen las consecuencias que pue- 
den tener las drogas, sean estas de tipo social, biológico y/o psicológico.

6. Posicionamiento ante las drogas: canciones que se posicionen de algún modo ante el mundo de las drogas (ya sea ante su venta, su consumo, las consecuencias...). Este posicionamiento puede ser a favor o en contra.

7. "Carpe diem" o "vivir al día": aquí incluimos la relación entre la droga y un modo de vida un tanto límite, donde lo que impere sea vivir el momento sin importar demasiado las posibles consecuencias.

8. Droga en el mundo de la música: letras referentes a que la droga forma parte del mundo de la música como elemento de moda o sustancia necesaria para tocar o desenvolverse.

9. Metáforas y comparaciones relacionadas con la droga: canciones donde aparece una metáfora o comparación en la que uno de los elementos es la droga o algo relacionado con ella, como sus consecuencias.

10. Relación entre la droga y diversos estilos de vida: temas donde la droga se menciona como un medio que hace que se pertenezca o se incluya en un determinado estilo o forma de vida.

Estos mensajes se han analizado por estilos musicales, cuando la muestra lo ha permitido. Obtuvimos conclusiones dentro de cada uno de los mensajes a dos niveles; conclusiones por estilos musicales y conclusiones generales del mensaje.

Por último, se han realizado las conclusiones finales que engloban la información de los diez mensajes en los cuatro estilos, conclusiones por supuesto obtenidas únicamente para la muestra seleccionada, también se ha realizado un análisis de los tipos de droga mencionada.

Es evidente también que el análisis y las conclusiones deben reducirse a una parte del fenómeno musical tanto en lo que respecta a estilos musicales como a los componentes fundamentales de lo musical ya que se analiza la letra y no la melodía o el ritmo de las canciones.

\section{RESULTADOS}

\section{A. ANÁLISIS POR ESTILOS MUSICALES}

\section{POP}

\section{Descripción muestra}

Se ha trabajado con un total de 27 intérpretes entre grupos y solistas, entre ellos nos encontramos 4 clasificados dentro del apartado denominado pop-latino y 1 en pop-flamenco. Dentro de esta categoría de música pop, no se ha descartado ningún artista ya que todos los revisados poseían algún tema que mencionaba las drogas.

Se han revisado un total de 58 trabajos discográficos (LPs), es decir, aproximadamente unas 600 canciones. De las cuales, han sido incluidas en nuestra investigación (por manifestar alguna referencia explícita a las drogas) un total de 99 (de las cuales 10 son de pop-latino y 5 de pop-flamenco), sin embargo, este número no constituye la muestra con la que hemos trabajado, sino que dicha muestra está formada por el número de mensajes o referencias que en las canciones se hace acerca de la droga, y esto es debido a que una misma canción puede contener más de un mensaje. Nuestra muestra de música pop, por tanto, es de un total de 190 mensajes sobre drogas.

El grupo que más frecuentemente aparece referido en los diferentes mensajes es Los Secretos, con 22 canciones, seguido de Los Rodríguez, con 9. Esta circunstancia puede ser debida al carácter intimista y personal con que dicho grupo impregnaba sus temas, reflejo de su propia relación con el mundo de la droga.

\section{Resultados y conclusiones}

Al hablar de droga en la música pop, parece realizarse de un modo sutil o encubierto, acercándose en ocasiones al lenguaje poético, dado que donde más referencias a la misma hemos hallado ha sido en las metáforas y comparaciones. El amor, la relación de pareja, la mujer, amistad, la fantasía y los ensueños, se parangonan con la droga y sus efectos (intoxicación, adicción, dependencia...), ocurriendo también al revés. Sin embargo, como hemos comentado anteriormente, dicha comparación varía dependiendo del aspecto, positivo o negativo, que se quiera enfatizar.

Los efectos que se buscan con la sustancia son diversos. En ocasiones, el consumo tiene como objetivo olvidar los problemas o disfrazar el dolor de alegría, por necesidad de la droga (dependencia o síndrome de abstinencia), y en general para afrontar las situaciones estresantes o negativas, dado que la droga actúa como desinhibidor de la conducta. Pero no debemos olvidar que también se consume para obtener bienestar, ser feliz.

Aunque en las canciones aparezca el consumo en soledad de la sustancia, la mayoría de las veces, la droga se presenta en el contexto del ocio y tiempo libre, produciéndose su uso y abuso con el fin de divertirse o estar a la moda o simplemente para emborracharse.

En el análisis de las letras pop analizadas, la droga que aparece principalmente es el alcohol, las referencias genéricas a las drogas aparecen en segundo lugar y en tercer lugar el tabaco. En el joven, al contrario de 
lo que sucede al adulto alcohólico, el alcohol tiene importantes efectos reforzantes, cobrando relevancia los efectos desinhibidores y euforizantes del mismo, en circunstancias sociales.

Durante esta etapa del desarrollo, el grupo de iguales pasa a ocupar un lugar destacado en la vida del individuo. La integración en el grupo se hace necesaria, y para lograrla hay que compartir experiencias y situaciones. Hay que seguir las normas del grupo, si no se produce la expulsión. A veces la droga es un instrumento aceptado que propicia las relaciones y la integración grupal. Esto, enlazaría con los mensajes a favor del consumo de sustancias que se lanza en algunas canciones, viéndose como una conducta positiva, aunque a veces también aparecen mensajes ambivalentes en este sentido.

El joven de nuestra sociedad muestra un patrón de consumo bastante característico, suele ser un bebedor de fines de semana, cuando bebe lo hace en grupo, en lugares de ocio y diversión, como discotecas, pubs y bares (aunque actualmente prolifera el beber en la calle o en alguna casa en la que no están los padres, son los llamados "botellones"), a veces con el objetivo de divertirse, emborracharse o acercarse al otro sexo. Y es que la búsqueda de sensaciones, el vivir el momento actual, la diversión, son características de esta etapa vital, o al menos eso es lo que comúnmente se sostiene. Sin embargo, la sociedad a la que pertenecemos se distingue por su carácter hedonista, y es que desde que nacemos intentamos evitar el dolor y buscar el placer. Así que, el análisis de las letras de las canciones, que en principio habla de lo cotidiano, podría ser un reflejo de esta realidad.

\section{ROCK}

\section{Descripción muestra}

Se han analizado 72 temas pertenecientes a un total de 17 representantes del estilo Rock. Estas 72 canciones fueron seleccionadas de una muestra total de 300 canciones aproximadamente, recogidas en 30 LPS. El análisis de estas 72 canciones, arroja un total de 105 referencias manejadas.

\section{Resultados y conclusiones}

El mensaje más representativo y, por tanto, más aparecido en la música Rock, es el que hace referencia a las consecuencias del consumo de drogas. Las letras hablan más de las consecuencias físicas, dejando más de lado las sociales. Tocan básicamente consecuencias a corto plazo, de las que se desprende cierta ambigüedad, o quedando claro si se consideran positivos o negativos sus efectos. Las consecuencias a largo plazo de las que se habla en los temas, son tan graves y drásticas como la muerte.
A este mensaje le sigue el de estilo de vida, en este sentido, las letras trasmiten la vinculación del consumo al estilo de vida y la sociedad, considerando a esta última culpable del mismo. Se banaliza incluso el problema de la droga, resaltando otros problemas sociales. Este estilo se ha caracterizado por la protesta reivindicativa de la sociedad en sus temas. También se habla del consumo como un hábito dentro de la rutina, dando un salto del consumo visto en el resto de los estilos del fin de semana.

En tercer lugar, y con el mismo porcentaje de representatividad, encontramos el mensaje que relaciona el consumo de sustancias con el ocio y la diversión. En los temas en que aparece este mensaje, se habla de la diversión, por la noche, con los amigos, en "garitos". El otro mensaje es el que hace referencia al posicionamiento respecto a la droga. Es significativamente mayor el porcentaje de letras que se posicionan explícitamente a favor de la droga, incitando a su consumo, o sugiriendo su normalización, incluso presentando como el trabajo más honrado el de traficante.

El resto de los mensajes son menos significativos, pero no por ello menos importantes. La droga para olvidar, como facilitador de relaciones sociales, y el proceso de drogadicción son los siguientes mensajes más aparecidos, por este orden.

De este modo, integrando todo, los mensajes que están llegando a la juventud española que escucha estos temas del Rock, es algo así como: Las consecuencias a corto plazo del consumo de drogas, son positivas o, en todo caso, ambiguas, a largo plazo son drásticas, pero queda mucho y hay que vivir el presente. El consumo es algo normal en la sociedad actual, y, además, está justificado, para olvidar lo injusta y lo dura que es la vida. Sin olvidar que es necesario para divertirse y llevarse bien con los amigos. Se presentan las drogas como un importante recurso para integrarse en la pandilla y solucionar los problemas. Teniendo en cuenta la vulnerabilidad de los adolescentes en este sentido, ¿qué influencia pueden tener estas letras en sus patrones de conducta y actitudes hacia las drogas?.

\section{PUNK}

\section{Descripción muestra}

Se analizaron 85 canciones de 10 grupos o cantantes punk; el análisis de estas 85 canciones arroja un total de 113 mensajes o referencias manejadas que constituyen la muestra considerada en el presente estudio, lo que significa que un total de 28 canciones tratan varios mensajes.

Así, el autor con más temas introducidos en la muestra es Manolo Kabezabolo, lo que no es de extrañar ya que este cantante vive en un psiquiátrico y solo sale de él a cantar y producir canciones, esta ingresa- 
do en el psiquiátrico de Zaragoza a consecuencia, precisamente, de su adicción a múltiples drogas.

También analizamos las canciones de otros dos grupos en los que no encontramos referencias, de los que se analizaron 12 canciones de cada grupo.

\section{Resultados y conclusiones}

Aunque el alcohol es la droga a la que más referencia se hace en las diferentes canciones, sorprende el elevadísimo número de apariciones de una droga como la heroína, tradicionalmente considerada como "dura" y asociada a lo marginal; también aparece con mucha frecuencia la marihuana y las anfetaminas; la droga en general sin especificar el tipo de droga (que en los otros estilos musicales es mucho más referenciada llegando a ocupar el segundo lugar en la mayoría de los análisis) aparece señalada en un lugar intermedio lo que puede estar reforzando la conclusión antes ya indicada de la mayor crudeza y dureza explícita así como al mayor reconocimiento e inserción del fenómeno droga en este estilo musical.

El tabaco prácticamente no aparece y las pastillas o la cocaína aparecen poco (drogas asociadas a determinados contextos sociales no comunes en los contextos culturales aquí referenciados), además, la cocaína aparece casi siempre asociada a la heroína.

Entre los términos asociados a las drogas encontramos el estar colocado, la raya (para referirse a la cocaína), las pápelas, el caballo o el chute (para referirse a la heroína), las pastillas o tripis (para referirse a las anfetaminas o a los alucinógenos) o la piedra, hierba, maría o canuto (en referencia a la marihuana). También aparecen términos como garito, la barra del bar, ir de marcha, la resaca o estar borracho.

En este estilo resalta sobre manera que se trate el tema de las drogas como algo cotidiano, frecuente e insertado en la vida cultural y las canciones que reflejan la misma.

Aparecen muchas referencias a drogas duras y a procesos de drogadicción severos, asociados con frecuencia a la marginalidad y exclusión social, a las cárceles o a la delincuencia; también con mucha frecuencia se hace referencia a varias drogas al tiempo, a la poli toxicomanía. Si a todo esto le unimos que, frecuentemente, no se habla del fenómeno de las drogas como problema, sino que se las inserta dentro de una funcionabilidad vital que ayuda a vivir y encontrar un sentido o que se mencionan efectos y consecuencias positivas y se llama a la legalización y normalización del consumo inserto en la vida cotidiana, el panorama que nos presentan la música punk con respecto a las drogas es un panorama de aceptación mayoritaria del fenómeno, de reconocimiento de su presencia, de consideración del proceso de drogadicción como un referente cercano.
Pero lo dicho no puede ni mucho menos llevarnos a concluir, por ejemplo, que en este estilo musical se produce una mayor relación con la droga; el punk es un estilo musical trasgresor, crítico, lejano de lo "políticamente correcto" y muchas veces de "lo popular" y cumple este papel también en el campo de las drogas, atendiendo y reflejando los procesos de consumo duros que tienen que ver con la exclusión, con la heroína fundamentalmente, abogando por la legalización o planteando contradicciones entre unos y otros consumos (por ejemplo los consumos de cocaína frente a los consumos de heroína). Que esto ocurra puede responder a que, simplemente y debido a los referentes y marcos conceptuales y culturales en los que este estilo musical se mueve, resulta más sencillo y aceptable hablar de las drogas como algo natural y presente en la realidad sin tener que ocultar el mismo en referencias indirectas.

La droga en este contexto es un elemento más de transgresión y provocación, de expresión de descontento; ayuda a encontrar sentido, se convive con ella con naturalidad y se refleja con frecuencia las canciones. Droga que se presenta en contextos de ocio, tanto como en contextos de marginación, en el tiempo libre y en el vivir de cada día, drogas que se combinan.

El lenguaje que se emplea es duro, las historias que se reproducen crudas, las realidades que se atienden y reflejan en las canciones los autores suelen tener que ver con otros procesos de deterioro y exclusión. Pero también, aparece con fuerza un polo expresivo que centrándose en la diversión, en vivir a tope, habla de las drogas riéndose de ellas, trivializando los consumos y normalizándolos.

\section{CANTAUTOR}

\section{Descripción muestra}

A la hora de seleccionar a los intérpretes que formarían parte de la investigación, se tuvo como criterio principal de selección que fueran de los más conocidos o bien de los que más vendían. El hecho de que no aparezcan determinados intérpretes no quiere decir que éstos no se hayan tenido en cuenta, sin embargo, tras revisarlos (Ej.: Aute o Antonio Vega), no se han encontrado referencias explicitas al tema de las drogas

El número de canciones revisadas fueron 350, de éstas, sólo 68 han pasado a formar parte de nuestra investigación. En cuanto a los intérpretes, se han revisado las composiciones de unos veinte artistas y finalmente se han incluido 13 cantautores únicamente.

El autor que más canciones aporto a esta investigación, fue Joaquín Sabina por dos motivos fundamentales: su gran repertorio de canciones comparados con otros intérpretes como Antonio Flores o Ismael Serrano y su estilo, donde no tiene repa- 
ros en hablar del sexo, el rock and roll y las drogas de forma clara y sin tapujos.

\section{Resultados y conclusiones}

El hecho de que el mensaje que más aparezca sea el de metáforas podríamos explicarlo recurriendo a la definición que normalmente se hace del cantautor como "poeta de la música". De hecho, J. Sabina el cantautor más nombrado dentro de toda nuestra investigación ha recibido en numerosas ocasiones el calificativo de "poeta urbano". Teniendo en cuenta que los cantautores son poetas, y que por norma general la poesía utiliza como recurso lingüístico, entre otras las metáforas es lógico que dentro de este género musical tengan un lugar destacado.

También dentro de las canciones de autor, nos encontramos con letras que nos hablan de temas tan dispares como puede ser la ecología, la libertad, pero también sobre el amor. Desde este punto de vista, el amor al ser un concepto tan amplio y tan abstracto para hablar sobre él en ocasiones se recurre a comparaciones, de este modo, cuando queremos resaltar su lado positivo, ese estado de enamoramiento, de euforia que el amor conlleva se suele recurrir a utilizar para explicarlo términos relacionados con los efectos de determinadas drogas, ¿Quién no ha oído nunca decir "estoy borracho de amor" como sinónimo de estoy enamoradísimo?. Pero por otra parte, el amor también se define como un estado de necesitar a la otra persona más que a nada en él mundo, sin la cual parece que uno no se puede vivir, éste hecho hace que para poder explicar esa "necesidad" se recurra a la relación de dependencia que se establece entre el drogodependiente y su sustancia de consumo.

Tras las metáforas, los dos mensajes que más se repiten son el relativo a "Droga para olvidar, superar dificultades o evadirse" y el de "Relación entre la droga y diversos estilos de vida".

En cuanto al primero, no resulta sorprendente puesto que es algo inherente a nuestra cultura que el mejor quitapenas parece ser el alcohol, aunque curiosamente no se buscan sus efectos más inmediatos como es la euforia sino se busca la embriaguez, para así poder olvidar mejor cualquier problema que se nos presente. Ante estos datos parece lógico que este mensaje haya quedado en segundo lugar dentro de las canciones analizadas.

Con referencia al segundo, cabe mencionar que hay una relación bastante estrecha entre el modo de vivir de una persona, sus hábitos y sus relaciones interpersonales. Así determinados contextos o ambientes son un factor de riesgo para el inicio o el consumo de determinadas sustancias. En contextos marginales, donde la delincuencia es frecuente, se da una estrecha relación entre ellos y droga, pero también se da entre gente más acaudalada y sometida a un fuerte estrés laboral. La diferencia entre estos contextos estribará en la sustancia de consumo. Mientras que en los contextos marginales la sustancia más consumida será la heroína, dentro del estilo de vida del famoso o del "yuppie" será la cocaína. Tampoco podemos olvidar al hablar de este mensaje del factor cultural en el consumo. Si dentro de la cultura occidental el consumo de alcohol es algo socialmente aceptado es lógico que se de una relación entre el estilo de vida del español y la bebida.

El siguiente mensaje más repetido es el de diversión y ocio. Vemos que la mayor parte de los adolescentes ocupan su tiempo libre con los amigos y que los lugares donde suelen reunirse con ellos son los bares, y que dentro de sus actividades está el pasárselo bien e ir de juerga.

También destacar que la droga más mencionada es el alcohol, y dentro de este la variedad de alcohol que más aparece es el vino seguido de las llamadas bebidas de alta graduación (whisky, ron). Resulta curioso, que la cerveza, la que más se consume y unas de las más baratas después del vino sea de las menos mencionadas.

Consideramos que el hecho de que el alcohol sea la droga más mencionada se debe, en primer lugar por ser una droga legal, de fácil disponibilidad y por supuesto por su aceptación social. De la misma manera desgraciadamente hay falsa conciencia de que esta no crea la dependencia, adición en comparación con las llamadas drogas duras (heroína y cocaína), y por tanto no hay peligro de convertirse en drogodependiente y uno puede dejar de beber cuando quiera. Esta actitud hacia el alcohol, mínimo poder adictivo, es compartida por el cannabis.

\section{B. ANÁLISIS POR MENSAJESY ESTILOS}

En el siguiente análisis (ver tabla 1) tendremos en cuenta los mensajes y los estilos:

- Por mensajes: el mensaje más frecuente es Consecuencias (20,83\%), seguido de Metáforas (13,64\%) y Droga y estilo de vida (13,33\%). Los mensajes menos tratados, en general, son "Carpe Diem" $(2,87 \%)$, Droga en la música $(3,37 \%)$ y Proceso de drogadicción $(5,97 \%)$. De un modo general se dan más mensajes con un posicionamiento positivo o a favor de la legalización que con uno negativo. Cuando relacionan la música con otros estilos de vida, se hace mayoritariamente con la marginación y la delincuencia.

\section{- Por estilos musicales:}

1) POP: en este estilo los mensajes que más se dan son Metáforas $(22,63 \%)$ y Consecuencias 
Tabla 1: Referencias en cada mensaje y en cada estilo musical (porcentajes)

\begin{tabular}{|c|c|c|c|c|c|c|c|c|c|c|c|}
\hline \multicolumn{2}{|l|}{$\begin{array}{l}\text { ESTILOS } \\
\text { MENSAJES }\end{array}$} & \multicolumn{2}{|c|}{ POP } & \multicolumn{2}{|c|}{ ROCK } & \multicolumn{2}{|c|}{ PUNK } & \multicolumn{2}{|c|}{ CANTAUTOR } & \multicolumn{2}{|c|}{ TOTAL } \\
\hline \multicolumn{2}{|c|}{ 1. Proceso drogadicción } & \multicolumn{2}{|c|}{4,21} & \multicolumn{2}{|c|}{5,71} & \multicolumn{2}{|c|}{11,5} & \multicolumn{2}{|c|}{2,46} & \multicolumn{2}{|c|}{$5,97 \%$} \\
\hline \multicolumn{2}{|c|}{ 2. Droga para olvidar... } & \multicolumn{2}{|c|}{11,58} & \multicolumn{2}{|c|}{8,57} & \multicolumn{2}{|c|}{3,5} & \multicolumn{2}{|c|}{16,04} & \multicolumn{2}{|c|}{$9,92 \%$} \\
\hline \multicolumn{2}{|c|}{ 3. Droga en el ocio... } & \multicolumn{2}{|c|}{6,84} & \multicolumn{2}{|c|}{11,42} & \multicolumn{2}{|c|}{12,3} & \multicolumn{2}{|c|}{12,34} & \multicolumn{2}{|c|}{$10,72 \%$} \\
\hline \multirow[t]{2}{*}{$\begin{array}{l}\text { 4. Droga y } \\
\text { relaciones }\end{array}$} & Sociales & 5,79 & 14,74 & 5,71 & 7,61 & 5,30 & 14,1 & 3,70 & 9,87 & $5,12 \%$ & $11,5 \%$ \\
\hline & Sexuales & 8,95 & & 1,90 & & 8,84 & & 6,17 & & $6,46 \%$ & \\
\hline \multicolumn{2}{|c|}{ 5. Consecuencias } & \multicolumn{2}{|c|}{18,42} & \multicolumn{2}{|c|}{40,95} & \multicolumn{2}{|c|}{14,1} & \multicolumn{2}{|c|}{9,87} & \multicolumn{2}{|c|}{$20,83 \%$} \\
\hline \multirow[t]{3}{*}{ 6. Posición } & Legalización & 1,05 & \multirow{3}{*}{9,47} & 3,80 & \multirow{3}{*}{11,42} & 7,07 & \multirow{3}{*}{12,3} & 0 & & $2,98 \%$ & \\
\hline & En contra & 2,63 & & 0,95 & & 0,88 & & 0 & 4,93 & $1,11 \%$ & $9,53 \%$ \\
\hline & A favor & 5,79 & & 6,66 & & 4,42 & & 4,93 & & $4 \%$ & \\
\hline 7. “Carpe Die & & & 74 & & & & & & & $2,85^{\circ}$ & \\
\hline 8. Droga en I & música & & 16 & & 30 & & & & & $3,7 \%$ & \\
\hline 9. Metáforas & & & 63 & & 35 & & & & 69 & 13,64 & \\
\hline $\begin{array}{l}\text { 10. Droga } \\
\text { estilo }\end{array}$ & $\begin{array}{l}\text { Marginación- } \\
\text { delincuencia }\end{array}$ & 1,58 & & 3,80 & & 8,84 & & 8,64 & & 5,71 & \\
\hline de vida & $\begin{array}{l}\text { Vida cotidiana } \\
\text { y cultura }\end{array}$ & 2,10 & 4,21 & 4,76 & 12,38 & 8,84 & 19,46 & 2,46 & 17,28 & $4,54 \%$ & $13,3 \%$ \\
\hline & $\begin{array}{l}\text { Porque la } \\
\text { droga }\end{array}$ & 0,53 & & 3,80 & & 1,76 & & 6,17 & & $3,06 \%$ & \\
\hline TOTAL & & & $0 \%$ & & $\%$ & & & & $\%$ & $100^{\circ}$ & \\
\hline
\end{tabular}

$(18,42 \%)$ y los que menos se dan son Droga en la música $(3,16 \%)$ y Proceso de drogadicción y Relación entre la droga y estilos de vida (ambos con 4,21).

2) ROCK: en este estilo el mensaje más abundante y con mucha diferencia es Consecuencias (40,95\%) seguido de lejos por Relación entre la droga y estilos de vida $(12,38 \%)$. Los mensajes menos señalados son "Carpe Diem" y Metáforas (2,85\%) seguidos de Droga en la música (3,80\%).

3) PUNK: aquí el mensaje que más aparece es Relación entre la droga y estilos de vida (19,46\%), tras este se encuentra Droga en las relaciones sociales y sexuales y Consecuencias $(14,1 \%)$, por el otro extremo se encuentran "Carpe Diem" (2,6\%) y Droga para olvidar... (3,5\%).
4) CANTAUTOR: se encuentran por arriba los mensajes Metáforas (24,69\%) y Relación entre la droga y estilos de vida $(17,28 \%)$. Por abajo están "Carpe Diem" y Droga en la música $(1,23 \%)$.

\section{ANÁLISIS POR TIPO DE SUSTANCIA Y ESTILO MUSICAL}

A continuación vamos a tener en cuenta el tipo de droga y el estilo musical:

-Existe una diferencia inmensa entre el alcohol y el resto de las drogas; es sin duda la más mencionada $(55,15 \%)$. El término droga en general y la heroína le siguen con $9,61 \%$ y $9,64 \%$ respectivamente. Las menos mencionadas son las metadona $(0,3 \%)$, la cafeína $(0,63 \%)$ y la cocaína $(3,79 \%)$. 
Tabla 2: Referencias a tipos de droga en cada estilo musical (Datos en porcentaje)

\begin{tabular}{|l|r|r|r|r|r|}
\hline TIPO DROGA & POP & ROCK & PUNK & CANTAUTOR & \multicolumn{1}{|c|}{ TOTAL } \\
\hline En general & 11,86 & 11,19 & 10,24 & 5,17 & $9,61 \%$ \\
Alcohol & 71,19 & 62,68 & 32,53 & 54,23 & $55,15 \%$ \\
Cafeína & 2,54 & - & - & - & $0,63 \%$ \\
Heroína & 1,69 & 2,98 & 18,67 & 15,25 & $9,64 \%$ \\
Cannabis & 0,85 & 4,47 & 15,06 & 6,77 & $6,78 \%$ \\
Anfetaminas & 0,85 & 2,98 & 16,56 & 5,08 & $6,36 \%$ \\
Cocaína & - & 2,98 & 5,42 & 6,77 & $3,79 \%$ \\
Metadona & - & - & 1,20 & - & $0,3 \%$ \\
Tabaco & 11,01 & 12,68 & 0,60 & - & $6,07 \%$ \\
\end{tabular}

- Por estilos:

1) POP: en primer lugar se menciona el alcohol $(71,19 \%)$ y a continuación la droga en general $(11,86 \%)$ y el tabaco $(11,01 \%)$. La cocaína y la metadona no se mencionan y el cannabis y las anfetaminas-speed-pastillas lo hacen muy levemente $(0,85 \%$ ambas).

2) ROCK: al igual que el pop los tipos de droga más mencionados son, alcohol (62,68\%), tabaco $(12,68 \%)$ y droga en general $(11,19 \%)$. No se menciona la cafeína ni la metadona y tras estas las menos señaladas son la heroína, las anfetaminas-speed-pastillas y la cocaína (las tres con un porcentaje de 2,98\%).

3) PUNK: la droga más nombrada pero con menor porcentaje que en los demás estilos es el alcohol $(32,53 \%)$, seguido de la heroína $(18,67 \%)$ y las anfetaminas-speed-pastillas (16,56\%). La cafeína no se menciona, y apenas lo hacen el tabaco $(0,60 \%)$ y la metadona (1,20\%, único estilo en el que aparece).

4) CANTAUTOR: de nuevo en primer lugar se encuentra el alcohol $(54,23 \%)$ y tras este la heroína $(15,25 \%)$, por abajo encontramos en primer lugar la cafeína, la metadona, y el tabaco, que no se mencionan y tras estos las anfetaminas-speed-pastillas $(5,08 \%)$ y la droga en general $(5,17 \%)$.

\section{DISCUSIÓN}

En primer lugar debemos señalar que cuando los temas musicales hablan de drogas, lo hacen tratando muy diferentes temáticas o tópicos. Esto hace que su análisis se haya sido dividido lo cual conlleva a que como en cualquier otro intento de clasificación perdamos parte de la información. En éste análisis, hemos extraído aquellas partes donde se habla de droga, aunque sin duda la información completa queda para cuando se escucha la canción entera (incluyendo elementos clave como el ritmo o la melodía), lo cual no quiere decir que sea tremendamente enriquecedor conocer como se habla de drogas en las canciones, pese a las limitaciones comentadas.

Con los resultados obtenidos, vemos como las consecuencias de la droga, sean psíquicas, físicas, a corto o a largo plazo, es el tema que más se menciona y se hace con mucha más frecuencia en el estilo rock. Esto podría interpretarse como un modo de aviso hacia no consumir, ya que "drogarse" tiene consecuencias, sin embargo, esto queda descartado cuando en general se esta dando un toque positivo hacia el consumo y la legalización, siendo muy limitadas las menciones en contra de la droga. Las consecuencias que se señalan son en gran parte consecuencias positivas y buscadas como ocurre con la borrachera.

Por otra parte, las canciones que nos hablan de un proceso completo en el que se observe el deterioro de la persona que consume podrían mandar un mensaje de cautela hacia el consumo, sin embargo, son pocos los temas que tratan el tema del proceso completo de drogadicción. En mayor medida se encuentran los mensajes que señalan que consumir (sobre todo alcohol) es un buen método tanto para divertirse como para olvidar o evadirse de la rutina y los problemas. En ocasiones la droga se asocia a un determinado estilo de vida, cuando lo hace en su mayoría es a la marginación y la delincuencia, pero también lo hace a un rol sexual masculino ("beber es de hombres"), y en otras ocasiones se asocia el consumo con el motivo directo que lo propicia.

El uso de metáforas con las drogas como uno de los elementos asociados es muy recurrido en las letras analizadas, no olvidemos que la música se considera un arte y dentro de esté también esta la poesía, que sin duda es el arte que más utiliza las metáforas. Éstas, dan un toque romántico y sutil al tema de las drogas, camuflan los mensajes de modo que en ocasiones han hecho que el propio autor de este trabajo se encuentre sorprendido del contenido de canciones 
que conocía ampliamente pero no había percibido que trataban de un tema de drogas. Esto puede estar sucediendo con muchas canciones que se conocen, se cantan, pero no se analizan.

Respecto a la comparación entre estilos podemos ver como estilos como el rock y el punk tratan de un modo más directo el tema de las drogas, sin utilizar metáforas, recurso utilizado mucho más ampliamente por el pop y sobre todo por los cantautores. La conexión entre la música y las drogas se realiza en mayor medida en el punk, quizá por la conocida drogodependencia de muchos de los cantantes y sin duda por la cultura que rodea a este estilo musical que propicia que se mencione abiertamente el tema sin tapujos. La delincuencia y la asociación con un estilo de vida propio es también más característico en el estilo punk, por los mismos motivos. También en este estilo se hacen más llamamientos hacia la legalización de la droga. Se hacen más menciones a la droga como facilitador de las relaciones sexuales en el pop, en los cantautores y en el punk, mientras que en el rock se mencionan más las relaciones sociales.

Estas diferencias en general, nos muestran que el estilo musical punk esta mucho más inmerso en un movimiento cultural y social que guarda relación directa con la droga y que además no muestra ningún reparo a la hora de mencionarlo. El resto de los estilos o bien no tienen tanta relación con la droga, o bien no lo comunican del mismo modo. No debemos olvidar que los demás estilos son más comerciales y culturalmente aún existe cierto "tabú" a la hora de hablar de drogas, que puede estar influyendo en que estos estilos no lo hagan, o si lo hacen sea de un modo más indirecto. Sin embargo, sí se ha visto que autores con reconocido consumo de drogas como (Los Secretos o Sabina) no tienen el mismo pudor a la hora de hablar del tema. En general la pregunta a hacerse es ¿en el "modo de vida punk" hay más droga que en otros estilos o es ese "modo de vida" el que propicia que se hable más de drogas?

Respecto al tipo de droga consumida, no cabe duda que es el alcohol la principal droga mencionada, las diferencias que le separan del resto de las drogas es inmensa. No olvidemos que el alcohol es una droga de aceptado consumo cultural y legalmente hablando, esto facilita que se consuma y también que se mencione libremente. No ocurre lo mismo con otras drogas como la heroína, cuyo consumo se relaciona más con un modo de vida marginal. El tabaco pese a ser otra droga legal no tiene la misma atención que el alcohol y su mención es escasa.

Las diferencias entre los estilos nos arrojan un dato importante. En general el alcohol es la primera droga mencionada en todos los estilos, pero en el estilo punk lo hace de un modo más discreto, cediendo terreno a otras, de modo que las menciones a los tipos de droga quedan más repartidas en este estilo.
En general el estilo punk habla de más drogas (alcohol, heroína, cannabis, anfetaminas-speed-pastillas...), el pop da también cabida al tabaco en gran número de canciones, al igual que el rock, sin embargo, los cantautores dan este segundo plano tras el alcohol a la heroína. En general el pop y el rock hablan de "drogas blandas" y el estilo cantautor y en especial el estilo punk lo hacen de "drogas duras".

Para concluir, puede señalarse que se habla de drogas en muchas ocasiones y cuando se hace, podemos decir que en general, se trata de un modo frívolo. Las drogas son algo divertido, que nos ayuda a pasarlo bien, a ligar, a salir con los amigos y también a olvidarnos de los problemas. En contadas ocasiones se muestran negativos hacia el consumo o se relatan las consecuencias plenas de una drogodependencia.

En que medida esto influye en el consumo, es difícil de determinar, y no es el objetivo del presente estudio. Sin duda, dentro del modelo teórico del que partimos, la música forma parte de la cultura juvenil, y la cultura es una de las muchas variables que influyen en la ingesta de drogas. Sin embargo, es muy interesante reflexionar acerca de qué nos trasmiten las canciones, y podría ser también un atractivo modo de trabajo con adolescentes con el fin de que realicen un análisis crítico de lo que escuchan y tararean diariamente al oír la radio o el cassette.

Sin duda, la aplicación práctica y preventiva de los resultados que se obtienen en el presente estudio de carácter descriptivo, será algo a desarrollar posteriormente; la música, como expresión cultural juvenil de primer orden, puede ser un elemento metodológico fundamental con el que acercarnos a los jóvenes y adolescentes potenciando la utilización de metodologías cercanas y más significativas lo que llevará a potenciar y optimizar las intervenciones preventivas en materia de drogodependencias. Pero este desarroIlo, será objeto de posteriores trabajos.

\section{BIBLIOGRAFÍA}

Calafat, A., Amengual, M. (1999). "Actuar es posible: Educación sobre el alcohol." Plan Nacional sobre Drogas. Secretaría General Técnica. Madrid.

Calafat, A., Fernández, C., Juan, M., Bellis, A., Bohrn, K. Hakkarainen, P., Kilfoyle- Carrington, M., Kokkevi, A., Maalsté N., Mendes, F. Siamou I., Simon J., Stocco P. y Zavatti, P. (2001) "Risk and control in the recreational drug culture" Sonar, 2000, Palma de Mallorca: IREFREA ESPAÑA

Calafat, A. Bohrn, K., Juan M, Kokkevi A, Maalsté, N., (1999) "Night life in Europe and recreative drug use" Sonar 98, Palma de Mallorca: IREFREA ESPAÑA 
Fuertes, J.C., Palacios, F. A. (1999). "Hablemos sobre las drogas." Madrid: ed. Arán. C.A.M. Agencia Antidroga y Asociación Carpe Diem.

Elzo, J.; Orizo, F. A., González Blasco, P. Del Valle, A. I. (1999) "Jóvenes españoles 1999" Fundación Santa María. Ediciones SM, Madrid.

Funes, J. (1996). "Drogas y adolescentes" Madrid: Editorial Aguilar.

Gamella, J.F., Alvarez Roldan, A., Romo, N. (1997). "La "fiesta" y el "éxtasis" drogas de síntesis y nuevas culturas juveniles." En Estudios de Juventud, № 40, 17-22.
Mayor.J. (1996). "Modelo sintético para comprender el proceso de drogadicción". Proyecto hombre n¹9. Madrid.

Pons, J., Berjano, E. (1999). "El consumo abusivo de alcohol en la Adolescencia: un modelo explicativo desde la psicología social". Madrid: Ministerio del Interior. Plan Nacional sobre Drogas.

Recio, P. D. (1997). "El fenómeno de la droga como capital simbólico y hecho social total." En Estudios de Juventud. № 40. Pág.. 9-16. 


\section{ANEXO 1: CANCIONES ANALIZADAS}

- Albert Pla: El lado más bestia de la vida; Mañana lo dejo; El bar de la esquina; Enterrador de cementerios; Añoro; Mujer mala; La nana de Antonio; Sufre como yo; Se canso; Que más da si de o no da

- Alejandro Sanz: Pisando fuerte; Canción sin emoción

- Amparo Sandino: Al final

- Ana Belén: Banana Republic

- Andrés Calamaro: Cuando te conocí

- Antonio Flores: Cuerpo de mujer; Nena

- Barón Rojo: Sombras de noche; Rock estimulación; ¿Dónde están mis amigos?; Ultima generación; Vamos muy bien

- Barricada: Blanco y negro

- Boicot: PGB; Quien cojones soy; Transgutoma; Isabel; Mentiras; Tequila; Inocente; Nos quieren detener

- Celtas Cortos: Tranquilo majete; Siempre igual; Si te gusta; República de Sanjes; Monólogo con ron; Legión de mudos; Ladrón de melodías; La senda del tiempo; Cálida trinchera;

- Danza Invisible: Laberinto de fortuna; La estanquera del puerto; Fiesta después de la fiesta; El club del alcohol; Diez razones para vivir; Amor de madre; A este lado de la carretera

- Def con Dos: Tú si que eres tonto; Cuidadano terrorista; Los reyes son los padres; Toponoto; Mineros locos; Que dice la gente; Muertos del rock; Vasos comunicantes

- Donato y Estéfano: Mariachis y tequila; De hombre a mujer; Cafeína

- Extremoduro: Buscando una luna; Tu corazón; Jesucristo García; La carrera; Me estoy quitando; Volando solo

- Gabinete Caligari: Soy como dos; La culpa fue del cha-cha-cha

- Hombres G: Tomate una copa; Si te vas; Mis amigos

- Inhumanos: Mujer caníbal; Yo no me voy de aquí; Que ciegos vais; Si pido una cerveza más

- Ismael Serrano: Vértigo; Donde estarán; La extraña pareja; Regresa; Vine de norte; Sin ti a mi lado

- Jarabe de palo: Toca mi canción; Vuela; La plaza de las palmeras; Esperando en mi rincón; el tiempo pasa;

- Javier Alvarez: Sunset Bulevar

- Joan Manuel Serrat: Decir amigo; Mediterráneo; Romance de Curro "El Palmo"; Sombras de la China

- Joaquín Sabina: Por el bulevar de los sueños rotos; Besos con sal; Mas de cien mentiras; Siete Crisantemos; Esta noche contigo; Eclipse de mar; Pobre Cristina; El muro de Berlín; Mentiras piadosas; Con un par; Con la frente marchita; Medias negras; Ponme un trago más; Rap del optimista; Así estoy yo sin ti; Hotel dulce hotel; Princesa; Pongamos que hablo de Madrid; Calle melancolía; Como decirte como contarte; Pacto entre caballeros; Ganas de; Barbi Superstar ; 19 días y 500 noches; Pero que hermosas eran; Donde habita el olvido; Como un explorador; No sopor, no soporto el rap

- Juan Perro: Cuando yo llegué a Santiago

- Ketama: Karta kanción para vivir; Kautivos en la noche; No estamos locos; Pokito a poko; Tran, tran, tran

- Kiko Veneno: Menphis Blues; Joselito; En un mercedes blanco

- Kortatu: La cultura; Mierda de ciudad; Equilibrio; Nivel 30

- La Polla Records: Conejas y gallinas; Confusión; Chica ye- ye; La revolución; Carne para la picadora; Herpes, talco y tecno- pop; Salve; Chus.

- La Polla: Palabra; Tu vida cambio

- Loquillo: Cadillac Solitario; Treinta y tantos; Hombres; Rompeolas; La matare; Rock and Roll Star

- Los Rebeldes: Mediterráneo

- Los Rodríguez: Soy como dos; Salud; Nunca me podré alejar de ti; Nada me han enseñado los años; La copa rota; Hace calor; Estoy vencido; Engánchate con migo; El marinero y el capitán; Aquí no podemos hacerlo; 
- Los Ronaldos: Por las noches; ¿Qué vamos a hacer?; Es verano

- Los Secretos: Volver a ser un niño; Sucedió al revés; Soy como dos; Quiero beber hasta perder el control; Ojos de gata; No seré yo; No sé si se acuerda; Niño mimado; Nacional Vl; Margarita; La ultima vida de un gato; Fuertes emociones; Cerrar los bares; Cambio de planes; Buena chica; Balsera; Algo más; Agárrate a mi María;

- Los Suaves: Pobre jugador; Al llegar la noche; Alguien morirá esta noche

- Mama Ladilla: Soy un fumador; Letras guarras; ¡Pobre principito;; Prebostes baratos; Primavera

- Maná: Clavado en un bar; Cahito; Ámame hasta que me muera

- Manolo (y los que se van...): El guru; Mata a tu viejo

- Manolo Kabezabolo; Casimiro; Sid Vicius Song; Camino del bar; Reptil gusano; Polako non did; MPM; Grito de rabia; Viva yo y mi caballo; El aborto de la gallina; Tuna punk; Tu vida cambió; Zensura; Kosas de viejas; A buen entendedor; Lomo con pimientos; Las gafas de sol; Ayer; Perlitas de gel; Resina, agua y ajo; Las coplillas; Nuestra única meta; Otra vez; Como siempre; Metidos en el ajo

- Manolo Tena: Marilyn Monroe; Fuego en la piel; Por derecho; Quiero beber y no olvidar

- Marco Masini: ¿Por qué lo harás?; Miedo de amarse

- Mecano: Hoy no me puedo levantar; El lago artificial; Barco a Venus

- Modestia aparte: Tomate una copa; Brumas

- Molotov: Más vale cholo

- Pabellón Psiquiátrico: En el cielo no hay alcohol

- Pedro Guerra: Rap /a /duras /penas; Hechos de gente; Siete puertas; Gente; Sobre la Luna; Adiós; La historia de Viola y el Barón; Viernes; Bahía; La Primera Morna; Bebes del Río; Cara y cruz.

- Platero y tú: Bobo; Voy a acabar borracho; ¿Cómo has perdido tú?; Sin solución; Tras la barra; Dan miedo las noches; Mendrugos; Marabao; Deltoya; Siesta de alcohol

- Porretas: Porretas; Jamón, queso, pan y vino; Ir sin nada; Compadre Ramírez; Joder que cruz; Que te pires; Exterminio (el último punki); Vas por libre; Marihuana; Si lo se me meo; Haciendo el ganso; Los doce mandamientos; Vaya día; Jeremías; Hortaleza; Antimilitar-Antisocial; Si bebes no conduzcas; Borracho; La chaqueta de un guardia; El abuelo fue picaor

- Ramoncín: Litros de alcohol

- Reincidentes: Rip-Rap

- Revólver: No hay droga más dura; Tu noche y la mía; Tu noche y mía

- Ricky Martín: La bomba; Livin' la vida loca; Lola, Lola; Bombón de azúcar

- Rosana: Bebes de mí

- Rosendo: Navegando

- Seguridad Social: El viajero; El hijo de mi padre; Amigo

- Sergio Dalma: Un cachito de ti; September night; ¿Qué harías tú?; Nuestra edad; Como cada mañana; Chicas veneno; Amor descafeinado; Adiós Sofía;

- Siniestro Total: Devorado; España se droga; Todo por la napia; La sociedad es la culpable; Ay Dolores; Hermano bebe

- SKAP: El hombre resaca; Legalización; Que chupones

- Sociedad Alcohólica: Aquí tirado; Dos historias; Amigos del bar; Lo tienes fácil; Intoxicación etílica; Dulce hogar; Garantía total; Como una roca; Maquinaria del Estado

- Talía: Mujer latina; Amor a la mejicana

- Tequila: Necesito un trago; Rock \& Roll en la plaza del pueblo

- Tontxu: Para tocar el cielo; Que fue de aquello; Copas en un bar; Madrid - Barcelona;

- Víctor Manuel: La madre 